RESEARCH REPORT

\title{
Influence of sociodemographic and neighbourhood factors on self rated health and quality of life in rural communities: findings from the Agriproject in the Republic of Ireland
}

\author{
Joseph B Tay, Cecily C Kelleher, Ann Hope, Margaret Barry, Saoirse Nic Gabhainn, Jane Sixsmith
}

J Epidemiol Community Health 2004;58:904-911. doi: 10.1136/jech.2002.006643

See end of article for authors' affiliations

Correspondence to:

Professor C Kelleher,

Department of Public

Health Medicine and

Epidemiology, Earlsfort

Terrace, University

College, Dublin 2,

Republic of Ireland; cecily.

kelleher@ucd.ie

Accepted for publication 26 January 2004
Objective: To examine the influence of sociodemographic and neighbourhood factors on self rated health, quality of life, and perceived opportunities for change (as one measure of empowerment) in rural Irish communities.

Design: Pooled data from cross sectional surveys two years apart.

Setting: Respondents in four randomly selected rural district electoral divisions with a population size of between 750 and 2000.

Participants: 1738 rural dwellers aged 15-93, 40.5\% men, interviewed at two time points.

Main outcome measures: Determinants of self rated health (SRH), quality of life (QOL), and perceived opportunities for change, rated on a closed option Likert scale and assessed in multivariate logistic regression models.

Main results: Overall $23.8 \%$ of the sample reported poor SRH, 22.2\% poor QOL, and $50.1 \%$ low perceived opportunities for change. Low financial security and dissatisfaction with work were each significantly associated with poor SRH (OR $=1.96$ (1.50 to 2.56$)$ and 1.54 (1.11 to 2.14)), with poor QOL $(O R=2.04$ (1.56 to 2.68) and 1.87 (1.34 to 2.61). Concern about access to public services was significantly predictive of $\mathrm{SRH}(\mathrm{OR}=1.47(1.11$ to 1.94$))$ rather than access to health care (that is, hospital and GP services). There were distinct sex specific patterns and a generational effect for educational status in men. Variables associated with social networks and social support were less strongly predictive of SRH and QOL when economic measures were accounted for.

Conclusion: Inter-relations between indicators of health status, wellbeing, and deprivation are not well studied in rural communities. Material deprivation has a direct influence on both health status and quality of life, although immediate sources of support are relatively well preserved.
W hile the relative importance of neo-material and psycho-social influences in determining health inequalities has been debated closely in recent years, ${ }^{12}$ research has largely focused on urban environments and settings, particularly in developed, industrialised countries. By contrast, our knowledge of rural health needs and inequality is comparatively limited..$^{3-7}$ In developing countries issues of fundamental deprivation and access to primary health care are foremost ${ }^{8}$ and in more affluent societies like Britain $^{6}$ and the United States, ${ }^{35}$ relative disadvantage through physical and infra-structural inadequacies predominate. The apparently weak link between deprivation and poor health in rural areas in some studies may be attributable to the inappropriateness of existing composite indicators of deprivation more suited to an urban setting. ${ }^{9-13}$ An example is car ownership, part of the Townsend deprivation index, ${ }^{14}$ which reflects wealth in urban environments but is a transport necessity, regardless of affluence, in many rural areas.

Rural dwellers are arguably disadvantaged because of geographical inaccessibility to health care and other public services, ${ }^{15-17}$ The consequences of this include reduced use of preventive services and hospital care because of the high costs and inconvenience of travel $^{16}$ and poorer health outcomes later. ${ }^{17}$ Such isolation can also be associated with lack of social support for those living and working alone or far from others, speculated to relate to increased suicide rates among rural dwellers.' Conversely, dense personal social networks such as close neighbours and family can protect people from stress and contribute to improved health. ${ }^{1}{ }^{18}$
Recent debates on the contextual importance of social and human capital $^{18}$ suggest that rural settings might have such advantages, through well preserved and integrated social networks and support. Haynes and Gale ${ }^{11}$ have shown that social variation in health in rural communities is apparent not at area but at individual household level. Barnett et $a l^{10}$ highlight the importance of exploring individual differences to better understand social variation in health in rural areas. Policies that apply resource allocation according to generic deprivation scores, not accounting for individual characteristics, may fail to address adequately the health needs of rural dwellers. The traditional rural landscape in industrialised economies is rapidly changing however with lengthy commuting patterns and increasing shortages of affordable housing for local people, compounding the complexity of the issues involved. ${ }^{\circ}$

In Ireland $42 \%$ of the population live in rural areas, three times the European average. ${ }^{19}$ There is a general shortage of data linking measures of affluence to health in Ireland. ${ }^{12}$ This is a basis for the work programme of the Health Research Board funded Unit of Health Status and Health Gain, that seeks to address the determinants of health status in that country. ${ }^{20-22}$ We have already pointed out that Ireland is of particular interest in the wider social capital debate, in having highly preserved indicators like family support and yet very poor health profiles. ${ }^{20}$ Medical card possession, a means tested entitlement to free general medical service, has served as a proxy for disadvantage and has been shown to be

Abbreviations: SRH, self rated health; $Q O L$, quality of life 
a consistent predictor of poor health in the general Irish population..$^{21}{ }^{22}$ The prevalence of medical card possession is much higher in rural areas $(42 \%)$ compared with the general population $(31 \%)$. Furthermore, because home ownership is very high in Ireland and many people with poor cash flow and low income might possess other assets, including small land holdings, the issue of assessing disadvantage is complex. ${ }^{12}$

Our objective therefore was to examine the influence of sociodemographic and neighbourhood factors on self rated health and quality of life in rural communities in Ireland, as part of an on-going programme of work on these issues.

\section{METHODS}

This analysis comprised survey data at two time points collected as part of the Agriproject health promotion intervention programme in four rural communities in the Republic of Ireland, details of which have been reported previously. ${ }^{23-26}$ This was a highly novel project in rural Ireland, one of whose objectives was to report the interrelations between social, economic, and working standards as related to measures of health and wellbeing. Carried out over five years (1996-2000), this project comprised two specific intervention elements, on farm safety in three communities ${ }^{25}$ and mental health ${ }^{26}$ mainly in one community, based on an initial needs assessment ${ }^{23}$ and community consultation process. ${ }^{24}$ The four rural communities participating in the study were selected at random in each province of Ireland from a list of rural district electoral divisions with populations of between 750-2000..$^{25}$ Both at the outset of the project and after two years a comprehensive interview administered questionnaire survey was undertaken of householders selected for participation. It was aimed to survey at least 250 people in each area on both occasions. Although a comparatively small sample in absolute terms it none the less represented high coverage of the candidate communities. Every second house in the village area and every house in the open countryside from each community were approached by researchers. Any household member over 15 years old was eligible to participate, with a maximum of four per household. Most households put forward only one respondent.

The questionnaire was devised for the project based largely on previously published instruments. It comprised sections on health and safety practice, measures of concern in relation to mental ill health (including help seeking in relation to suicide and depression) as well as information on attitudes to

\begin{tabular}{|c|c|c|c|}
\hline Characteristic & 1997 & 1999 & Total \\
\hline [Base category] & $\%(\mathbf{n})$ & $\%(n)$ & $\%(\mathbf{n})$ \\
\hline \multicolumn{4}{|l|}{ Demographic } \\
\hline Male & $39.2(397)$ & $42.3(307)$ & $40.5(704)$ \\
\hline [Female] & $60.8(615)$ & 57.7 (419) & $59.5(1034)$ \\
\hline \multicolumn{4}{|l|}{ Entitlement to medical card } \\
\hline Yes & $44.4(445)$ & $39.5(285)$ & $42.3(730)$ \\
\hline$[\mathrm{No}]$ & $55.6(557)$ & $60.5(437)$ & $57.7(994)$ \\
\hline \multicolumn{4}{|l|}{ Perceived financial security } \\
\hline Low & 30.7 (309) & $27.7(201)$ & $29.4(510)$ \\
\hline [Medium or High] & $75.3(759)$ & $75.0(545)$ & 70.6 (1222) \\
\hline \multicolumn{4}{|l|}{ Years lived in area } \\
\hline$<15$ years & $26.1(262)$ & $28.5(206)$ & $27.1(468)$ \\
\hline [16-90 years] & $73.9(742)$ & $71.5(516)$ & $72.9(1258)$ \\
\hline \multicolumn{4}{|l|}{ Marital status } \\
\hline Single & $31.3(316)$ & $36.9(268)$ & $33.6(584)$ \\
\hline [Married/Widow/Other] & $68.7(695)$ & $63.1(459)$ & $66.4(1154)$ \\
\hline \multicolumn{4}{|l|}{ Children } \\
\hline Yes & $63.0(632)$ & $58.6(416)$ & $61.2(1048)$ \\
\hline [No] & $37.0(371)$ & $41.4(294)$ & $38.8(665)$ \\
\hline \multicolumn{4}{|l|}{ Education } \\
\hline Primary or lower & $29.2(295)$ & $21.8(158)$ & $26.1(453)$ \\
\hline [Secondary or higher] & $70.8(714)$ & $78.2(568)$ & $73.9(1282)$ \\
\hline \multirow{2}{*}{\multicolumn{4}{|c|}{$\begin{array}{l}\text { Personal social networks } \\
\text { Lack of close neighbours }\end{array}$}} \\
\hline & & & \\
\hline Very concerned/Concerned & $23.0(231)$ & $19.5(141)$ & $21.6(372)$ \\
\hline [Not at all/Not concerned] & 77.0 (773) & $80.5(581)$ & $78.4(1354)$ \\
\hline \multicolumn{4}{|l|}{ Limited opportunities to meet others } \\
\hline Very concerned/Concerned & $25.4(255)$ & 24.0 (174) & $24.8(429)$ \\
\hline [Not at all/Not concerned] & $74.6(750)$ & $76.0(550)$ & $75.2(1300)$ \\
\hline \multicolumn{4}{|l|}{ External social networks } \\
\hline \multicolumn{4}{|l|}{ Distance to health care } \\
\hline Very concerned/Concerned & $28.5(288)$ & $30.6(220)$ & $29.4(508)$ \\
\hline [Not at all/Not concerned] & 71.5 (721) & $69.4(498)$ & 70.6 (1219) \\
\hline \multicolumn{4}{|l|}{ Distance to shopping opportunities } \\
\hline Very concerned/Concerned & $12.6(127)$ & $14.2(103)$ & $13.2(230)$ \\
\hline [Not at all/Not concerned] & $87.4(883)$ & $85.8(623)$ & $86.8(1506)$ \\
\hline \multicolumn{4}{|l|}{ Lack of public services } \\
\hline Very concerned/Concerned & $35.2(354)$ & $32.2(234)$ & $33.9(588)$ \\
\hline [Not at all/Not concerned] & $64.8(652)$ & $67.8(492)$ & $66.1(1144)$ \\
\hline \multicolumn{4}{|l|}{ Psychosocial } \\
\hline \multicolumn{4}{|l|}{ Satisfaction with work } \\
\hline Very dissatisfied/dissatisfied & $14.0(140)$ & $14.3(101)$ & $14.1(241)$ \\
\hline [Very satisfied/satisfied] & $86.0(863)$ & $85.7(604)$ & $85.9(1467)$ \\
\hline \multicolumn{4}{|l|}{ Health behaviours } \\
\hline \multicolumn{4}{|l|}{ Smoking } \\
\hline Smoker/Ex-smoker & $44.1(445)$ & $43.6(316)$ & $43.9(761)$ \\
\hline [Never smoker] & $55.9(564)$ & $56.4(409)$ & $56.1(973)$ \\
\hline
\end{tabular}


Table 2 Percentage low response on self rated health, QOL, and perceived opportunities for change by potential predictive variables

\begin{tabular}{|c|c|c|c|}
\hline & $\begin{array}{l}\% \text { With low } \\
\text { SRH (n) }\end{array}$ & $\begin{array}{l}\% \text { With low self rated } \\
\text { QOL (n) }\end{array}$ & $\begin{array}{l}\% \text { With low self rated } \\
\text { perceived empowerment } \\
\text { (n) }\end{array}$ \\
\hline \multicolumn{4}{|l|}{ Sex } \\
\hline Male & $23.1(162)$ & $21.2(148)$ & $46.4(324)$ \\
\hline Female & $24.3(251)$ & $22.9(236)$ & $52.6(538)$ \\
\hline $\mathrm{p}$ & 0.566 & 0.410 & 0.012 \\
\hline \multicolumn{4}{|l|}{ Medical card } \\
\hline Yes & $26.2(191)$ & $27.2(198)^{*}$ & $52.1(376)$ \\
\hline No & $22.2(220)$ & $18.6(184)$ & $48.8(482)$ \\
\hline $\mathrm{p}$ & 0.052 & 0.000 & 0.186 \\
\hline \multicolumn{4}{|l|}{ Perceived financial security } \\
\hline High & $18.1(221)^{*}$ & $16.4(199)^{*}$ & $44.5(538)^{*}$ \\
\hline Low & 37.5 (191) & $35.9(183)$ & $63.4(321)$ \\
\hline p & 0.000 & 0.000 & 0.000 \\
\hline \multicolumn{4}{|l|}{ Years in area } \\
\hline Shortest time & $23.8(111)$ & $18.2(85)$ & $50.4(234)$ \\
\hline Other & 23.7 (298) & $23.5(294)$ & $49.8(855)$ \\
\hline p & 1.000 & 0.022 & 0.828 \\
\hline \multicolumn{4}{|l|}{ Marital status } \\
\hline Single & $27.7(161)$ & $25.1(146)$ & $50.4(290)$ \\
\hline Married/Widow/Other & $21.9(252)$ & $20.7(238)$ & $50.0(573)$ \\
\hline \multirow{2}{*}{\multicolumn{4}{|c|}{ Children }} \\
\hline & & & \\
\hline Yes & $22.1(231)$ & $21.1(220)$ & $49.3(513)$ \\
\hline No & $26.2(174)$ & $24.0(159)$ & $51.1(336)$ \\
\hline \multirow{2}{*}{\multicolumn{4}{|c|}{$\begin{array}{l}\mathrm{p} \\
\text { Education }\end{array}$}} \\
\hline & & & \\
\hline Primary or less & $23.5(106)$ & $24.7(111)$ & $48.1(215)$ \\
\hline Secondary or more & $23.9(306)$ & $21.3(272)$ & $50.9(647)$ \\
\hline \multirow{2}{*}{\multicolumn{4}{|c|}{$\begin{array}{l}\text { p } \\
\text { Lack of close neighbours }\end{array}$}} \\
\hline & & & \\
\hline Concerned & $24.3(90)$ & $27.8(103)$ & $54.7(202)$ \\
\hline Not concerned & $23.8(321)$ & $20.7(279)$ & $29.1(658)$ \\
\hline p & 0.837 & 0.005 & 0.060 \\
\hline \multicolumn{4}{|l|}{ Opportunities to meet others } \\
\hline Concerned & $28.3(121)$ & $29.3(125)^{*}$ & $54.4(231)$ \\
\hline Not concerned & $22.4(290)$ & $19.9(258)$ & $48.9(631)$ \\
\hline \multirow{2}{*}{\multicolumn{4}{|c|}{$\begin{array}{l}\mathrm{p} \\
\text { Distance to health care }\end{array}$}} \\
\hline & & & \\
\hline Concerned & $23.3(118)$ & 23.5 (119) & $55.3(277)^{\star *}$ \\
\hline Not concerned & $23.9(291)$ & $21.6(262)$ & $48.2(583)$ \\
\hline \multirow{2}{*}{\multicolumn{4}{|c|}{$\begin{array}{c}\mathrm{p} \\
\text { Distance to shops }\end{array}$}} \\
\hline & & & \\
\hline Concerned & $28.1(64)$ & $26.6(61)$ & $52.4(120)$ \\
\hline Not concerned & $23.2(349)$ & $21.5(323)$ & $49.8(743)$ \\
\hline \multirow{2}{*}{\multicolumn{4}{|c|}{$\begin{array}{c}p \\
\text { Lack of public services }\end{array}$}} \\
\hline & & & \\
\hline Concerned & 27.1 (159) & $24.5(143)$ & $55.0(319)$ \\
\hline Not concerned & $21.9(250)$ & $20.9(239)$ & $47.5(540)$ \\
\hline \multirow{2}{*}{\multicolumn{4}{|c|}{ Satisfaction with work }} \\
\hline & & & \\
\hline Satisfied & $20.9(306)^{*}$ & $19.6(286)^{*}$ & $44.5(538)^{\star}$ \\
\hline Not satisfied & 39.0 (94) & $37.5(90)$ & $63.1(321)$ \\
\hline $\mathrm{p}$ & 0.000 & 0.000 & 0.000 \\
\hline SRH & & & \\
\hline Low & - & $40.1(165)^{*}$ & $46.4(608)^{*}$ \\
\hline High & - & $16.6(218)$ & $62.0(254)$ \\
\hline$p$ & - & 0.000 & 0.000 \\
\hline Self rated QOL & & & \\
\hline Low & $43.1(165)^{*}$ & - & $63.5(244)^{*}$ \\
\hline High & $18.3(246)$ & - & $46.2(616)$ \\
\hline & 0.000 & - & 0.000 \\
\hline Opportunities for change & & & \\
\hline Low & $29.5(254)^{*}$ & $28.4(244)^{*}$ & - \\
\hline High & $18.2(156)$ & $16.4(140)$ & - \\
\hline $\mathrm{p}$ & 0.000 & 0.000 & - \\
\hline Smoking (tobacco) & & & \\
\hline Never & $21.6(209)$ & 20.4 (198) & $50.1(483)$ \\
\hline Current/ex smoker & $26.5(201)$ & $24.4(185)$ & $50.1(376)$ \\
\hline $\mathrm{p}$ & 0.019 & 0.047 & 1.000 \\
\hline
\end{tabular}

health and wellbeing more generally, quality of life indicators and sociodemographic information. The two surveys, carried out in 1997 ( $\mathrm{n}=1007,39.4 \%$ male) and $1999(\mathrm{n}=1051$, $40.8 \%$ male) served as a needs analysis and impact assessment of the interventions respectively. The needs assessment process in the communities highlighted concerns about farm safety and mental health issues and hence these formed the focus of the intervention. ${ }^{24}$ The process and 
impact findings of these interventions, based particularly in schools, farms, and small scale enterprises, have been reported elsewhere and are not considered further here. ${ }^{25} 26$

For this analysis we wished to examine the influence of social, demographic, and lifestyle factors on self rated health and wellbeing. A series of questions regarding personal social networks and so called external social networks were recorded. Respondents were asked to rate their concern on a five point Likert scale (not at all concerned, not concerned, uncertain, concerned, and very concerned) in relation to lack of close neighbours, limited opportunities to meet others, distance to healthcare facilities, shopping opportunities, and lack of public services. They were also asked to rate their satisfaction with work and with level of financial security (very satisfied, satisfied, uncertain, dissatisfied, and very dissatisfied). The following were also recorded; age last birthday, sex, means tested entitlement to a general medical services card, marital status (single, married, widow, or other), children or not, level of education (primary, secondary, or tertiary). Smoking status (current, former, or never) was included as it is known to relate both to socioeconomic status and health.

We selected three outcome variables, an approach consistent with other analyses conducted as part of the unit for health status and health gain programme. Self rated health (SRH), an established health outcome, ${ }^{27-40}$ is a strong predictor of general morbidity and mortality including diverse factors such as poor functional ability, mortality, increased physician visits and hospitalisations, and survival in cancer. SRH has inverse associations with socioeconomic group, ${ }^{33}$ level of education, ${ }^{34}$ individual affluence, ${ }^{35}$ and less consistently, income inequality. ${ }^{36}$ The relation between SRH and indicators of deprivation varies according to gender within and between countries. ${ }^{37-40}$ We have stratified our analysis by sex in recognition of these differences. Respondents were asked to respond as very satisfied, satisfied, uncertain, dissatisfied, or very dissatisfied with respect to how they felt about their health and physical condition.
Measures of quality of life (QOL) have often been used to measure functional wellbeing and health in groups suffering from chronic illness or specific diseases. ${ }^{31}{ }^{32}$ We use an adaptation of Cantrill's Ladder ${ }^{41}$ to evaluate the impact of characteristics like dense social networks and poor public services on rural QOL. Respondents indicated a score from one (as bad as it could possibly be) to ten (as good as it could possibly be) to describe their QOL. The scores were quartiled such that the people with scores in the lowest quartile were classified as having poor QOL.

Self empowerment, the third domain, can be defined as the means, ability, or power people have to change their social reality. ${ }^{42}$ Although the concept of personal empowerment is widely used in the literature, particularly by the health promotion movement, ${ }^{43}{ }^{44}$ there is surprisingly little information on well validated measures. Deconstructing these determinants has great significance for the implementation of successful health promotion interventions that require individual and community empowerment as a prerequisite. ${ }^{44}$ The determinants of empowerment for change in rural communities are not well delineated, although a person's social circumstance is an important component in some groups. ${ }^{45}$ To capture in simple terms a sense of control in relation to their circumstances, respondents in the Agriproject were asked how satisfied they were with opportunities to change things around them that they did not like, a question selected because it was used previously in a rural community survey. ${ }^{46}$

Because the variables used here were not part of the intervention protocol we did not anticipate significant change between the two surveys. As there were no differences in average values at pre-intervention and post-intervention stages (table 1) and no significant between community variations it was therefore decided that it would be acceptable to combine time 1 and time 2 data to increase power for the subsequent analysis. Respondents who participated in both years $(n=312)$ were removed, resulting in a sample size of 1738 independent observations (40.5\% male). While there are small differences between the two

Table 3 Predictors of poor self rated health in the overall population and in men and women

\begin{tabular}{|c|c|c|c|c|c|c|}
\hline & \multicolumn{2}{|l|}{ Overall } & \multicolumn{2}{|l|}{ Men } & \multicolumn{2}{|l|}{ Women } \\
\hline & Odds ratio $(95 \% \mathrm{Cl})$ & $\mathbf{p}$ & Odds ratio $(95 \% \mathrm{Cl})$ & $\mathbf{p}$ & Odds ratio $(95 \% \mathrm{Cl})$ & $\mathrm{p}$ \\
\hline \multicolumn{7}{|l|}{ Demographic variables } \\
\hline Age & - & 0.000 & - & 0.000 & - & 0.000 \\
\hline Male & 0.909 (0.696 to 1.186$)$ & 0.481 & - & - & - & - \\
\hline With medical card & $1.037(0.788$ to 1.365$)$ & 0.797 & 0.937 (0.584 to 1.505 ) & 0.789 & $1.079(0.763$ to 1.526$)$ & 0.669 \\
\hline Dissatisfied with financial security & 1.959 (1.502 to 2.555$)$ & 0.000 & 2.036 (1.329 to 3.117$)$ & 0.001 & 2.016 (1.422 to 2.857$)$ & 0.000 \\
\hline$<15$ years in area & 0.969 (0.722 to 1.301$)$ & 0.834 & 1.176 (0.719 to 1.922 ) & 0.519 & 0.860 (0.591 to 1.252$)$ & 0.432 \\
\hline Single & $1.347(0.850$ to 2.137$)$ & 0.205 & 1.630 (0.762 to 3.486$)$ & 0.208 & 1.259 (0.688 to 2.302$)$ & 0.455 \\
\hline With children & 1.187 (0.774 to 1.822$)$ & 0.431 & 1.695 (0.805 to 3.572 ) & 0.165 & $0.955(0.563$ to 1.619$)$ & 0.863 \\
\hline Primary school or less & $1.203(0.826$ to 1.752$)$ & 0.335 & 1.126 (0.631 to 2.007$)$ & 0.688 & 1.333 (0.804 to 2.209 ) & 0.265 \\
\hline \multicolumn{7}{|l|}{ Social network 1} \\
\hline $\begin{array}{l}\text { Concerned, lack of close } \\
\text { neighbours }\end{array}$ & 0.811 (0.579 to 1.137 ) & 0.225 & 0.734 (0.408 to 1.318$)$ & 0.300 & 0.872 (0.574 to 1.324$)$ & 0.520 \\
\hline $\begin{array}{l}\text { Concerned, limited opportunities } \\
\text { to meet others }\end{array}$ & $1.210(0.879$ to 1.665$)$ & 0.242 & $0.897(0.507,1.587)$ & 0.708 & 1.461 (0.986 to 2.166$)$ & 0.059 \\
\hline \multicolumn{7}{|l|}{ Social network 2} \\
\hline $\begin{array}{l}\text { Concerned, distance to health } \\
\text { care }\end{array}$ & 0.840 (0.645 to 1.005$)$ & 0.554 & 0.994 (0.545 to 1.467$)$ & 0.659 & 0.746 (0.435 to 0.960$)$ & 0.531 \\
\hline $\begin{array}{l}\text { Concerned, distance to shopping } \\
\text { opportunities }\end{array}$ & $0.880(1.030$ to 0.699$)$ & 0.880 & $0.923(0.472$ to 1.808$)$ & 0.816 & $1.133(0.699$ to 1.835$)$ & 0.612 \\
\hline $\begin{array}{l}\text { Concerned, lack of public services } \\
\text { Psychosocial }\end{array}$ & 1.471 (1.114 to 1.941$)$ & 0.006 & 1.803 (1.158 to 2.807$)$ & 0.009 & $1.269(0.884$ to 1.821$)$ & 0.197 \\
\hline Dissatisfied with work & $1.543(1.111$ to 2.145$)$ & 0.010 & 1.629 (0.956 to 2.776$)$ & 0.073 & $1.476(0.962$ to 2.266$)$ & 0.075 \\
\hline Low score on $\mathrm{QOL}$ in general & $2.506(1.905$ to 3.296$)$ & 0.000 & $2.324(1.472$ to 3.671$)$ & 0.000 & 2.708 (1.907 to 3.844$)$ & 0.000 \\
\hline $\begin{array}{l}\text { Low perceived empowerment } \\
\text { Health risk behoviour }\end{array}$ & 1.529 (1.185 to 1.973$)$ & 0.001 & 1.903 (1.255 to 2.885$)$ & 0.002 & $1.358(0.975$ to 1.892$)$ & 0.071 \\
\hline $\begin{array}{l}\text { Health risk behaviour } \\
\text { Smoker/ex smoker }\end{array}$ & 1.348 (1.045 to 1.739$)$ & 0.022 & $1.793(1.178$ to 2.730$)$ & 0.006 & $1.165(0.834$ to 1.628$)$ & 0.371 \\
\hline
\end{tabular}


Table 4 Predictors of low quality of life in the overall population and men and women

\begin{tabular}{|c|c|c|c|c|c|c|}
\hline & \multicolumn{2}{|l|}{ Overall } & \multicolumn{2}{|l|}{ Men } & \multicolumn{2}{|l|}{ Women } \\
\hline & Odds ratio $(95 \% \mathrm{Cl})$ & $p$ & Odds ratio $(95 \% \mathrm{Cl})$ & $p$ & Odds ratio $(95 \% \mathrm{Cl})$ & $\mathbf{p}$ \\
\hline \multicolumn{7}{|l|}{ Demographic variables } \\
\hline Age & - & 0.000 & - & 0.000 & - & 0.000 \\
\hline Male & 0.889 (0.677 to 1.168$)$ & 0.398 & - & - & - & - \\
\hline With medical card & 1.360 (1.030 to 1.797$)$ & 0.030 & 1.261 (0.788 to 2.017$)$ & 0.333 & 1.293 (0.908 to 1.842$)$ & 0.154 \\
\hline Dissatisfied with financial security & $2.043(1.558$ to 2.679$)$ & 0.000 & 1.988 (1.283 to 3.081$)$ & 0.002 & $2.126(1.491$ to 3.030$)$ & 0.000 \\
\hline$<15$ years in area & 0.663 (0.484 to 0.909$)$ & 0.011 & 0.671 (0.384 to 1.171$)$ & 0.160 & $0.662(0.447$ to 0.980$)$ & 0.039 \\
\hline Single & $1.257(0.781$ to 2.024$)$ & 0.346 & 0.785 (0.371 to 1.663$)$ & 0.528 & $1.600(0.852$ to 3.004$)$ & 0.144 \\
\hline With children & $1.168(0.752$ to 1.812$)$ & 0.490 & 0.698 (0.337 to 1.443$)$ & 0.332 & 1.594 (0.908 to 2.798$)$ & 0.105 \\
\hline Primary school or less & $1.204(0.827$ to 1.753$)$ & 0.332 & 1.850 (1.044 to 3.277$)$ & 0.035 & 0.931 (0.557 to 1.556$)$ & 0.786 \\
\hline \multicolumn{7}{|l|}{ Social network 1} \\
\hline $\begin{array}{l}\text { Concerned, lack of close } \\
\text { neighbours }\end{array}$ & 1.191 (0.855 to 1.659$)$ & 0.302 & $1.373(0.780$ to 2.416$)$ & 0.272 & $1.103(0.725$ to 1.677$)$ & 0.648 \\
\hline $\begin{array}{l}\text { Concerned, limited opportunities } \\
\text { to meet others }\end{array}$ & 1.490 (1.081 to 2.055$)$ & 0.015 & $1.309(0.740$ to 2.315$)$ & 0.355 & 1.561 (1.046 to 2.330$)$ & 0.029 \\
\hline \multicolumn{7}{|l|}{ Social network 2} \\
\hline $\begin{array}{l}\text { Concerned, distance to health } \\
\text { care }\end{array}$ & $0.876(0.641$ to 1.197$)$ & 0.406 & $1.059(0.632$ to 1.774$)$ & 0.827 & 0.802 (0.539 to 1.192$)$ & 0.275 \\
\hline $\begin{array}{l}\text { Concerned, distance to shopping } \\
\text { opportunities }\end{array}$ & 1.008 (0.678 to 1.497$)$ & 0.970 & 1.596 (0.824 to 3.095$)$ & 0.166 & $0.768(0.463$ to 1.276$)$ & 0.309 \\
\hline Concerned, lack of public services & $1.054(0.790$ to 1.406$)$ & 0.722 & 0.911 (0.567 to 1.463$)$ & 0.700 & 1.199 (0.829 to 1.733$)$ & 0.335 \\
\hline Self rated health & 2.488 (1.890 to 3.275$)$ & 0.000 & $2.211(1.392$ to 3.510$)$ & 0.001 & 2.709 (1.909 to 3.845$)$ & 0.000 \\
\hline \multicolumn{7}{|l|}{ Psychosocial } \\
\hline Dissatisfied with work & $1.870(1.337$ to 2.615$)$ & 0.000 & 1.750 (0.993 to 3.081$)$ & 0.053 & 2.085 (1.360 to 3.194$)$ & 0.001 \\
\hline Low perceived empowerment & $1.463(1.126$ to 1.901$)$ & 0.004 & $2.130(1.384$ to 3.276$)$ & 0.001 & 1.143 (0.815 to 1.603$)$ & 0.439 \\
\hline \multicolumn{7}{|l|}{ Health risk behaviour } \\
\hline Smoker/ex smoker & 0.802 (0.618 to 1.040$)$ & 0.096 & 0.839 (0.547 to 1.288 ) & 0.423 & $0.815(0.581$ to 1.144$)$ & 0.237 \\
\hline
\end{tabular}

samples (table 1), particularly in education level of participants, these are unlikely to be a result of the intervention programme.

Before multivariate analysis, $\chi^{2}$ tests were used to evaluate the relation between the three dependent indicative measures chosen and potential predictor variables. Exact significance values are reported and additionally a standard Bonferroni correction of 17 was made to adjust the $\alpha$ level to 0.003 to account for the large number of tests. Binary logistic regression was then carried out using all selected variables to determine the predictors of poor SRH, QOL, and low perceived opportunities for change. All variables were dichotomised (the two lowest points compared with the rest) to facilitate the modelling and interpretation process and cut off points selected are presented clearly in the tables. Three stepwise multivariate logistic regression models were then constructed for each of the three outcome variables, reported overall, adjusting for age and sex and for each sex separately. As each domain was modelled, the other two were included as independent variables. Age was included as a covariate in all the models. SPSS Version 10 was used throughout. All statistical tests were two tailed and 95\% confidence intervals are reported for all odd ratios as well as exact $\mathrm{p}$ values.

\section{RESULTS}

Overall $23.8 \%$ of respondents reported poor SRH, $22.2 \%$ poor QOL, and 50.1\% low perceived opportunities for change. At bi-variate level (table 2) a number of factors appeared associated with poor SRH, including medical card eligibility, being single, and current smoking. Those concerned about opportunities to meet others and with lack of public services also tended to rate their health poorly. However, none of these factors is significant with Bonferroni adjustment. Those not satisfied with work $(\mathrm{p}<0.0001)$, with poor QOL $(\mathrm{p}<0.0001)$, with low perceived financial security $(\mathrm{p}<0.0001)$, and low perceived opportunities for change $(p<0.0001)$ were highly significantly likely to rate their health poorly.
A low self rated QOL tended to be associated with being longer in an area, concern about lack of close neighbours, and among current smokers, but these did not remain significant after Bonferroni correction. Medical card holders $(p<0.0001)$, those with poor SRH $(p<0.001)$, those with low perceived opportunities for change $(\mathrm{p}<0.0001)$, those dissatisfied with work $(p<0.0001)$, those concerned about opportunities to meet others $(\mathrm{p}<0.001)$, and with low perceived financial security $(p<0.0001)$, were all significantly more likely to report a poor QOL. More women than men tended to report low opportunities for change but this was not significant after Bonferroni correction. Those with low perceived opportunities for change were significantly more likely to report low financial security $(\mathrm{p}<0.0001)$, work dissatisfaction $(\mathrm{p}<0.0001)$, poor SRH $(\mathrm{p}<0.0001)$, and poor $\mathrm{QOL}$ $(\mathrm{p}<0.0001)$.

Tables 3 to 5 contain the results of the overall and sex stratified logistic regression analysis for SRH, QOL, and perceived opportunities for change respectively. Low financial security and dissatisfaction with work each remained strongly associated with the three dependant variables, poor SRH, low QOL, and low perceived opportunities for change after controlling for all other demographic variables. In the case of both men and women low level of financial security doubled the odds of reported poor health (OR 2.036 and 2.016 respectively) and low QOL (OR 1.988 and 2.126). Those with low level of financial security were also more likely to perceive low opportunity for change (OR $=1.621$ for men and $\mathrm{OR}=2.247$ for women). As suggested by the bivariate tests, medical card possession was not independently significant except in the quality of life model ( $\mathrm{OR}=1.360$ overall). Those with a poor SRH were also more concerned about lack of public services $(\mathrm{OR}=1.471)$, more likely to be smokers $(\mathrm{OR}=1.348)$, and to report also low QOL $(\mathrm{OR}=2.506)$. Those with a low QOL were also more concerned about opportunities to meet others $(\mathrm{OR}=1.490)$, more likely to report poor SRH $(\mathrm{OR}=2.488)$, and low perceived opportunities for change $(\mathrm{OR}=1.463)$.

Some gender differences are observed in each of the three domains in the sex specific age adjusted models. For 
Table 5 Predictors of low perceived opportunities for change in the overall population and in men and women

\begin{tabular}{|c|c|c|c|c|c|c|}
\hline & \multicolumn{2}{|l|}{ Overall } & \multicolumn{2}{|l|}{ Men } & \multicolumn{2}{|l|}{ Women } \\
\hline & Odds ratio $(95 \% \mathrm{Cl})$ & $\mathbf{p}$ & Odds ratio $(95 \% \mathrm{Cl})$ & $\mathrm{p}$ & Odds ratio $(95 \% \mathrm{Cl})$ & $\mathbf{p}$ \\
\hline \multicolumn{7}{|l|}{ Demographic variables } \\
\hline Age & - & 0.000 & - & 0.000 & - & 0.000 \\
\hline Male & $0.830(0.666$ to 1.034$)$ & 0.097 & - & - & - & - \\
\hline With medical card & $1.025(0.814$ to 1.290$)$ & 0.836 & $1.638(1.103$ to 2.432$)$ & 0.014 & $0.760(0.568$ to 1.017$)$ & 0.064 \\
\hline Dissatisfied with financial security & $1.952(1.139$ to 1.921$)$ & 0.000 & $1.621(1.110$ to 2.363$)$ & 0.012 & $2.247(1.636$ to 3.086$)$ & 0.000 \\
\hline$<15$ years in area & $1.076(0.844$ to 1.371$)$ & 0.554 & $1.270(0.836$ to 1.928$)$ & 0.262 & $0.939(0.691$ to 1.276$)$ & 0.687 \\
\hline Single & $0.883(0.605$ to 1.289$)$ & 0.519 & $0.840(0.451$ to 1.563$)$ & 0.582 & $0.858(0.519$ to 1.416$)$ & 0.549 \\
\hline With children & $0.828(0.585$ to 1.171$)$ & 0.287 & $0.719(0.392$ to 1.317$)$ & 0.285 & $0.908(0.589$ to 1.400$)$ & 0.662 \\
\hline Primary school or less & $0.749(0.551$ to 1.018$)$ & 0.065 & $0.447(0.276$ to 0.726$)$ & 0.001 & $1.101(0.728$ to 1.665$)$ & 0.648 \\
\hline \multicolumn{7}{|l|}{ Social network 1} \\
\hline Concerned, lack of close neighbours & $1.112(0.837$ to 1.478$)$ & 0.463 & $1.378(0.842$ to 2.254$)$ & 0.202 & $0.990(0.693$ to 1.413$)$ & 0.954 \\
\hline Concerned, limited opportunities to meet others & s $1.043(0.790$ to 1.377$)$ & 0.765 & $0.836(0.511$ to 1.365$)$ & 0.473 & $1.215(0.860$ to 1.716$)$ & 0.269 \\
\hline \multicolumn{7}{|c|}{ Social network 2} \\
\hline Concerned, distance to health care & $1.318(0.924$ to 1.595$)$ & 0.062 & $1.220(0.800$ to 1.861$)$ & 0.356 & $1.338(0.971$ to 1.844$)$ & 0.075 \\
\hline Concerned, distance to shopping opportunities & $0.825(0.590$ to 1.153$)$ & 0.259 & $0.987(0.540$ to 1.803$)$ & 0.966 & $0.699(0.462$ to 1.057$)$ & 0.089 \\
\hline Concerned, lack of public services & $1.157(0.913$ to 1.464$)$ & 0.227 & $1.214(0.826$ to 1.783$)$ & 0.323 & $1.125(0.829$ to 1.526$)$ & 0.449 \\
\hline Self rated health & $1.513(1.173$ to 1.953$)$ & 0.001 & $1.855(1.223$ to 2.813$)$ & 0.004 & $1.368(0.982$ to 1.904$)$ & 0.064 \\
\hline \multicolumn{7}{|l|}{ Psychosocial } \\
\hline Dissatisfied with work & $1.444(1.059$ to 1.969$)$ & 0.020 & $1.228(0.737$ to 2.045$)$ & 0.430 & 1.739 (1.164 to 2.598$)$ & 0.007 \\
\hline Low score on $\mathrm{QOL}$ in general & $1.479(1.139$ to 1.921$)$ & 0.003 & $2.170(1.412$ to 3.336$)$ & 0.000 & $1.146(0.817$ to 1.606$)$ & 0.431 \\
\hline \multicolumn{7}{|l|}{ Health risk behaviour } \\
\hline Smoker/ex smoker & $1.029(0.833$ to 1.271$)$ & 0.793 & $1.232(0.875$ to 1.735$)$ & 0.233 & $0.981(0.743$ to 1.295$)$ & 0.891 \\
\hline
\end{tabular}

instance, smoking status $(\mathrm{OR}=1.793)$ and having low perceived opportunities for change $(\mathrm{OR}=1.903)$ appear primarily associated with the SRH of men. Men with low perceived opportunities for change $(\mathrm{OR}=2.130)$ and less than a primary school education $(\mathrm{OR}=1.850)$ tended to report low QOL, although men with a primary education were less likely to report low levels of perceived opportunities for change $(O R=0.447)$. Stratification showed that this latter effect was present only in men over 45 years of age (data not shown). Dissatisfaction with work was more strongly associated with low perceived opportunities for change among women $(\mathrm{OR}=1.739)$ whereas a low score on QOL was more clearly associated with this variable in men $(\mathrm{OR}=2.170)$.

\section{DISCUSSION}

This is a novel study in that there is comparatively little information in the international literature on the interrelation between measures of health status, wellbeing, and socioeconomic status in more traditional rural based communities in developed industrialised economies. ${ }^{4}{ }^{18}$ This is of particular relevance in public policy terms as the directionality of the relation between material disadvantage and social cohesion is both important and difficult to identify. ${ }^{12}$ An assumption to be tested in relation to urban disadvantage is

\section{Key points}

- Health inequalities research in rural settings is not widely reported and indicators of deprivation used in urban studies may be inappropriate.

- Although aspects of community networks and support are influential, measures of material circumstances such as financial security and work satisfaction consistently predict SRH, QOL, and perceived opportunities for change.

- There are clear gender and secular differences in determinants of SRH, QOL, and perceived opportunities for change. that it might be alleviated by policy initiatives that promote community development. Accordingly situations with high levels of social integration coexisting with material disadvantage are of considerable interest.

We have shown in this analysis that there are clear interrelations, as might be expected, between social circumstances and each of the three domains we examine, but satisfaction with work and financial security consistently and independently predict SRH, QOL, and perceived opportunities for change, emerging more strongly than the indicators of neighbourhood networks and support. This would seem to indicate that health research, policy, and interventions in rural areas must be tailored to the particular sociodemographic composition of rural populations and take independent account of their material needs. Our findings do not imply that social capital and cohesion are unimportant. Traditional rural communities enjoy more dense social and family networks than urban communities and the evidence points to a protective effect of this for health. ${ }^{145}$ However, basic material factors like financial security are directly influential, not just for health and wellbeing but arguably in empowerment terms too, if the proxy we use here, of perceived opportunities for change, can be taken as a reasonable measure of at least one aspect of this concept.

Our findings do show that concerns about social amenities play a part, independently, on perceived health and wellbeing and that there are demographic differences. It is increasingly acknowledged that deprivation indices should take account of geographical access to services, as is the case in the United Kingdom. The Scottish index of multiple deprivation for instance comprises income deprivation,

\section{Policy implications}

- Policies directed at rural communities should focus on individual disadvantage and should be targeted to the needs of specific groups.

- Area based strategies should take a concerted approach, ensuring a focus on material disadvantage rather than on social capital strategies alone. 
employment deprivation, health deprivation and disability, education, skills and training deprivation, and geographical access to services (http://www.scotland.gov.uk/library5/ social/siod-04.asp, accessed 29 May 2003). The services included are road distance to a GP surgery or health centre, general store or supermarket, primary school, petrol station, bank or building society, and community internet facilities. Notably car ownership is not included.

This analysis distinguishes between health care and all other public services. People in rural Ireland, as in parts of Scotland, experience poor access to health care, particularly specialised treatments such as coronary artery bypass grafts and angioplasties. ${ }^{47}{ }^{48}$ We find however that it is poor access to general public services such as the police, ambulance or fire services and not specifically health care, that has an impact on these respondents. This may arguably reflect low perceptions of personal risk among rural dwellers for health problems requiring complex interventions. Similar low perceptions of risk have been observed in rural communities for heart disease, sun exposure, and skin cancer. ${ }^{46}{ }^{47}$ Road traffic accidents on the other hand require the rapid response of emergency services, which may imprint acutely on community awareness and therefore be perceived as a more immediate threat to health. A culture of self sufficiency may also help explain this observation and is a potentially positive aspect of rural communities. It has been shown that older Irish people particularly, differentiate clearly between health maintenance strategies and healthcare provision and are sceptical about younger people's dependence on medical services for minor ailments. ${ }^{49}$

The value of studying rural communities in particular depth is highlighted by the fact that GMS or medical card eligibility, in contrast with other studies we have reported ${ }^{20-22}$ is not as important a predictor of self rated health, although it is associated with QOL. One suggested explanation is the higher than average rates of eligibility among countrydwellers, compared with urban areas, at $42 \%$ of the total sample. It is very possible that eligibility in urban areas is a harder measure of disadvantage than in a rural setting. The means testing entailed in distributing medical cards may not account for softer means of economic support common in rural Ireland such as for instance the seasonal provision of tourist accommodation. It highlights also the importance in studies of poverty and disadvantage of identifying robust measures of economic wealth that include factors other than current income.

There are subtle but important differences according to age, gender, and educational status in this analysis. Untailored personal development interventions may have a lesser impact then would be expected if directed at specific groups and contexts and this should be taken into consideration when rural health research and community interventions are undertaken. Low perception of opportunities for change does not have an impact on the health and quality of life of rural women generally but is influenced by their satisfaction with work situations. Secular influences must also be accounted for. For example, men over 45 years of age with primary education only, appeared to have better opportunities for change than their better educated counterparts, although with lower SRH and QOL. This is almost certainly explained by the fact that this group of men was educated before free secondary school education was introduced in 1967. Before that farmers and agricultural workers of all levels of affluence were likely to leave school earlier than they would today so that education as a measure of relative disadvantage has changed over time. Before the Free Scheme, most rural men did not expect to depart from the traditional occupations of their fathers. Families sought to ensure that their children acquired a class position that did not fall lower than their own. ${ }^{50}$ The introduction of free secondary education in Ireland has had an important impact on the subsequent social development in the country but it also means that educational status might not be as sensitive a measure of disadvantage among older people as it is for younger adults. ${ }^{21}$

There are acknowledged limitations in that the study was primarily designed as an intervention project, although the data we report on here are novel and form part of a secondary analysis programme for the Unit on Health Status and Health Gain. Moreover, the interventions, tailored specifically to farm safety in three communities and to promotion of positive attitudes to mental health issues mainly in one community, could have had little meaningful impact on the variables in question, not least because there were no between community differences at either time point in the factors under analysis here. The sample selection process was at the level of household and therefore not truly random, and it contains more women than men but it represents comparatively high coverage of the small population candidate communities and we were stringent in applying a Bonferroni statistical correction with a high level of statistical significance to avoid spurious associations. In a larger scale survey effects of modest magnitude might have remained independently predictive but notwithstanding this their impact was not as pronounced as the indicators of affluence. We also acknowledge the limitation of our proxy measure for empowerment but find it interesting none the less that it relates so consistently to health, wellbeing, and measures of material affluence. Both SRH and QOL are now well established measures and our findings are broadly in keeping with the literature.

In conclusion, this analysis highlights the importance of material and compositional factors in the health of rural individuals and communities, suggesting that health promotion policy strategies should attend to both context and composition rather than either alone.

\section{Authors' affiliations}

J B Tay, A Hope, M Barry, S N Gabhainn, J Sixsmith, Centre for Health Promotion Studies, Department of Health Promotion, Clinical Science Institute, National University of Ireland, Galway, Republic of Ireland

Funding: the Agriproject was a five year intervention programme funded by the Health Promotion Unit, Department of Health and Children, the Health and Safety Authority and a research Fellowship bursary from the Medical and Scientific Committee of the Freemasons of Ireland. The actual interventions were supported by the local health boards and various statutory and voluntary agencies, particularly Teagasc. This analysis forms part of a work programme of the Health Research Board of Ireland funded Unit on Health Status and Health Gain. Dr Joseph Tay was a post-doctoral researcher on the PRTLI funded Human Impact Cluster of the Environmental Change Institute.

Conflicts of interest: none declared.

\section{REFERENCES}

1 Marmot MG, Wilkinson RG. The social determinants of health. Oxford: Oxford University Press, 1999.

2 Lynch J, Davey Smith G, Hillemeier M, et al. Income inequality, the psychosocial environment and health: comparisons of wealthy nations. Lancet 2001;358:194-200

3 Auchincloss $\mathbf{A H}$, Hadden $\mathrm{W}$. The health effects of rural-urban residence and concentrated poverty. J Rural Health 2002;18:319-36.

4 Taylor LC. Work attitudes, employment barriers and mental health symptoms in a sample of rural welfare recipients. Am J Community Psychol 2001;29:443-63.

5 Geronimus AT, Bound J, Waidmann TA. Poverty, time and place: variation in excess mortality across selected US populations 1980-90. J Epidemiol Community Health 1999;53:325-34.

6 Darton D, Hirsh D, Strelitz J. Tackling disadvantage. A 20 year enterprise. York: Joseph Rowntree Foundation Working Paper, 2003.

7 Bloom G. Equity in health in unequal societies. Meeting health needs in contexts of social change. Health Policy 2001;57:203-24. 
8 Klaser S. Poverty, inequality and deprivation in South Africa: an analysis of the 1993 Saldnu survey. Social Indicators Research 1997;41:51-94.

9 Kelleher MJ, Keely HS, Corcoran P. The service implications of regional differences in suicide rates in the Republic of Ireland. Ir Med J 1997:90:262-4.

10 Barnett S, Roderick P, Martin D, et al. A multilevel analysis of the effects of rurality and social deprivation on premature limiting long term illness. $J$ Epidemiol Community Health 2001;55:44-51.

11 Haynes R, Gale S, Lovett A, et al. Mortality, long term illness and deprivation in rural and metropolitan wards of England and Wales. Health and Place 1999;5:301-2

12 Howell F, O'Mahoney M, Devlin J, et al. A geographical distribution of mortality and deprivation. Ir Med J 1993;86:96-99.

13 Haynes R, Gale S. Deprivation and poor health in rural areas: inequalities hidden by averages. Health and Place 2000;6:75-285.

14 Townsend P. Deprivation. J Soc Policy 1987;16:125-46.

15 Fearn R. Rural health care: a British success or tale of unmet need? Soc Sci Med 1987; 24:263-74.

16 Haynes R, Bentham G, Lovett A, et al. Effects of distances to hospital and GP surgery on hospital inpatient episodes, controlling for needs and provision. Soc Sci Med 1999;49:425-533.

17 Jones A, Bentham $G$. Health service accessibility and deaths from asthma in 402 local authority districts in England and Wales, 1988-92. Thorax 1997:52:218-22

18 Frohlich KL, Corin E, Potvin L. A theoretical proposal for the relationship between context and disease. Sociology of Health and Illness 2001;23:776-97.

19 Department of Agriculture and Food, Government of Ireland. Ensuring the future-a strategy for rural development in Ireland. A white paper on rural
development. Dublin: Department of Agriculture and Food, Government of Ireland, 1999.

20 Kelleher C, Friel S, Nic Gabhainn S, et al. Socio-demographic predictors of self rated health in the Republic of Ireland: findings from the National Survey on Lifestyle, Attitudes and Nutrition, SLAN. Soc Sci Med 2003;57:477-86.

21 Kelleher C, Timoney A, Friel S, et al. Indicators of deprivation, voting patterns and health status at area level in the Republic of Ireland. J Epidemiol Community Health 2002;56:36-44.

22 Kelleher CC, Harrington J, Friel S. Measures of self reported morbidity according to age, gender and general medical services eligibility in the national survey of lifestyles, attitudes and nutrition. Ir J Med Sci 2002;171:134-7.

23 Hope A, Kelleher C, Holmes L, et al. Health and safety practices among farmers and other workers: a needs assessment. Occup Med 1999:49:231-5.

24 Barry M, Doherty A, Hope A, et al. A community needs assessment for rural mental health promotion. Health Educ Res 2000;15:293-304.

25 Kelleher C, Hope A, Barry M, et al. Health, safety and wellbeing in rural communities in the Republic of Ireland: main results from the Agriproject. Galway: Centre for Health Promotion Studies, NUI Galway, 2001.

26 Barry M, Friel S, Dempsey C, et al. Promoting mental health and social wellbeing: cross border opportunaties and challenges. Armagh: Centre for Cross Border Studies, 2001.

27 Ferraro KF, Farmer MM, Wybraniec JA. Health trajectories: long term dynamics among black and white adults. J Health Soc Behav 1997;38:38-54

28 Robin J, McAvay G. Determinants of change in perceived health in a longitudinal study of older adults. J Gerontal B Psychol Sci Soc Sci 1992;47:373-84.
29 Menec WH, Chipperfield JG, Perry RP. Self-perceptions of health: a prospective analysis of mortality, control, and health. Sci Soc Sci 1999;54B:85-93

30 Idler El, Benyamini Y. Self-rated health and mortality: a review of twentyseven community studies. J Health Soc Behav 1997;38:21-37.

31 Coates A, Porzsolt F, Osoba D. Quality of life in oncology practice: prognostic value of EORTC QLQ-C30 scores in patients with advanced malignancy. Eur J Cancer 1997;33:1025-30.

32 Melberg K. Farming, stress and psychological well-being: the case of Norweigan farm spouses. Sociologia Ruralis 2003;43:56-9,

33 Kunst AE, Geurts JJM, van den Berg J. International variations in socioeconomic inequalities in self reported health. J Epidemiol Community Health 1995:49:117-23.

34 Sundquist J, Johansson SE. Self reported health and low educational level predictors for mortality: a population based follow up study of 39,156 people in Sweden. J Epidemiol Community Health 1997;51:35-40.

35 Shibuya K, Hashimoto H, Yano E. Individual affluence, affluence distribution, and self rated health in Japan; cross sectional analysis of nationally representative sample. BMJ 2002;324:16.

36 Kennedy B, Kawachi I, Glass R, et al. Affluence distribution, socioeconomic status, and self rated health in the United States: multilevel analysis. BMJ 1998;317:917-21.

37 Bartley M, Sacker A, Firth D. Fitzpatrick, R. Social position, social roles and women's health in England: changing relationships 1984-1993, Soc Sci Med 1999;48:99-115.

38 Matthews S, Manor O, Power C. Social inequalities in health: are there gender differences? Soc Sci Med 1999;48:49-60.

39 Hraba J, Lorenz F, Lee G, et al. Gender differences in health: evidence from the Czech Republic. Soc Sci Med 1996;43:1443-51.

40 Fuhrer $\mathbf{R}$, Stansfield SA. How gender affects patterns of social relations and their impact on health: a comparison of one or multiple sources of support from "close persons". Soc Sci Med 2002;54:811-25.

41 Cantril H. The pattern of human concerns. New Brunswick, NJ: Rutgers University Press, 1965

42 Naidoo J, Wills J. Health promotion foundations for practice. 2nd ed. London: Bailliére Tindall, 2000.

43 Laverack G, Wallerstein N. Measuring community empowerment: a fresh look at organizational domains. Health Promotion International $2001 ; 16: 179-85$

44 Labonte R. Health promotion and empowerment: reflections on professional practice. Health Educ Q 1994;21:253-68.

45 Fisher C. To dwell among friends. Chicago: University of Chicago Press, 1982.

46 Malenga B. The health beliefs and skin cancer prevention practices of Wisconsin dairy farmers. Oncol Nursing Forum 1995;22:681-6.

47 Bury G, Dowling J. Community cardiac awareness teaching in a rural area: he potential for a health promotion message. Resuscitation 1996;33:141-5.

48 Nic Gabhainn S, Murphy A, Kelleher C. A national general practice census: characteristics of rural general practices. Fam Pract 2001;18:622-6.

49 MacFarlane A, Kelleher C. Concepts of illness causation and attitudes to health care among older people in the Republic of Ireland. Soc Sci Med 2002; 54:1389-400.

50 Breen R, Goldthrope J. Explaining educational differential: towards a formal rational theory. Rationality and Society 1997:9:75-305. 